\title{
En defensa de los individuos humanos concretos
}

Luis Armando González ${ }^{1}$

Recibido en Diciembre 2012, aprobado en Mayo 2013

“Nunca debemos detener nuestra búsqueda crítica de la verdad [...], debemos procurar siempre aprender de aquellos que sostienen una opinión diferente".

Karl Popper

\begin{abstract}
Resumen
El autor recuerda en este artículo, que cada individuo concreto es una realidad cuya integralidad biológica es crucial tanto para su humanización como para su dignificación. Desde esta perspectiva, si importa la dignidad y humanidad de las personas, la integralidad biológica de cada cual debe protegerse porque sin ella su humanización y dignificación reales son prácticamente imposibles.
\end{abstract}

\section{Palabras claves}

Individualismo económico, Autonomía individual, Debate racional y crítico, Infantilismo religioso, Neo conservadurismo, integralidad biológica.

\begin{abstract}
The author highlights that every single person is a reality whose biological totality is crucial to be humanized and dignified. Such view recognizes the importance of dignity and the human condition of individuals whose biological integrality must be protected; otherwise, their humanization and dignity would be impossible.
\end{abstract}

\section{Keywords:}

Economic individualism, individual autonomy, rational and judgmental debate, religious naiveness, neo-conservatism, biological integrality

1. Director de la Escuela Superior de Maestros (ESMA) del Ministerio de Educación de El Salvador. E-mail:luisgest@gmail.com. 


\section{Introducción}

En 1967 fue publicada, por la editorial Grijalbo, la edición española del libro Marxismo e individuo humano, del marxista polaco Adam Schaff. En los círculos marxistas ortodoxos de Europa y América Latina, el libro de Schaff no cayó en gracia. En esos tiempos, reivindicar al individuo en los círculos comunistas era contrario a los dogmas establecidos, empecinados en afirmar lo colectivo a expensas de lo individual, sin entender que la dimensión individual no excluye la dimensión social, sino que la incluye concretándola. Por estos senderos se decanta la exploración que realiza el marxista polaco, que se esfuerza por dar a los individuos concretos el lugar que les corresponde en la estructura social. Se trató de una apuesta filosófica de envergadura, que le valió a Schaff ser etiquetado de burgués, liberal y reaccionario.

Durante mucho tiempo se creyó que las mayores amenazas contra el individuo humano provenían de dogmatismo marxista-leninista. Por eso, una vez que el "socialismo real" (bautizado así por Adam Schaff) se derrumbó, cobró vigencia la tesis de que éste encontraría en el capitalismo reinante las mejores condiciones para su desarrollo. Sin embargo, esta tesis ha sido desmentida en distintas experiencias históricas enmarcadas en el capitalismo neoliberal de nuestra época.

En efecto, en distintos contextos capitalistas no sólo el individualismo (consumista y posesivo) ha ahogado el desarrollo integral de los individuos, impidiendo su realización como seres humanos plenos, sino que se defiende un individualismo económico, pero en el plano cultural se hace todo por impedir la autonomía individual, la libertad de elegir el propio estilo de vida, la tolerancia y el debate racional y crítico sobre cualquier asunto de interés individual y colectivo. Es decir, la libertad individual que se promueve y defiende en la esfera económica se ataca y condena en la esfera cultural y moral, en la cual se busca imponer el oscurantismo y la irracionalidad por la vía de tabúes y mitos anclados en un infantilismo religioso pernicioso para las personas. En el plano moral cultural, en fin, se quiere impedir, como quería Kant, que las personas decidan por sí mismas y alcancen, así, su mayoría de edad.

En este sentido, la defensa de los individuos humanos sigue siendo algo actual y necesario. El (neo) conservadurismo de derecha no sólo quiere ahogar su libertad moral e intelectual, sino que promueve una visión de la realidad humana ajena a los dinamismos biológicos, psicológicos y sociales que constituyen la realidad propia de cada individuo humano, en su vinculación genética y en vinculación social con sus congéneres. Estas páginas tienen como propósito resistir las acechanzas del (neo) conservadurismo en contra de los individuos humanos concretos. 


\section{El peligro del fanatismo}

Es bueno y hasta necesario que haya personas que asuman la defensa de causas religiosas, éticas o políticas. Y es que si no hubiera causas por las cuales luchar -y no hubiera personas que lo hicieran- se perdería mucho del compromiso individual y colectivo que hace que la realidad social se mueva en una cierta dirección. Pero hay un riesgo en esto de asumir causas por los cuales luchar: el fanatismo. No es inevitable eso de defender fanáticamente una causa pero, cuando se la absolutiza, la caída en el fanatismo es casi automática.

El fanatismo es, además de una traba para resolver los problemas reales de sociedad, un peligro en el plano del conocimiento y en el plano de las actitudes y prácticas a las que da lugar. Veamos algunos rasgos del fanatismo.

Primero, absolutiza la situación o problema que tiene en la mira, y que es la que alienta su causa. Es decir, en la visión de la realidad que tiene el fanático no hay nada más importante (o trascendental) que aquello que le preocupa, y ante lo cual todo lo demás es totalmente irrelevante y prescindible. Junto con esto, la propia interpretación que hace el fanático del problema que tiene ante sí y la solución que él (o ella) proclama son las únicas posibles en términos absolutos. No hay otra forma de entender el problema ni otra solución que las sostenidas por la persona que es presa del fanatismo. Él o ella tienen la "verdad", lo cual quiere decir que todos los que sostienen una visión distinta del problema y su solución están en el error.

En segundo lugar, y como consecuencia de lo anterior, el debate y el diálogo -entendidos como mecanismos para lograr un mejor conocimiento y para corregir las visiones equivocadas de la realidad- no tienen ninguna utilidad ni pertinencia para las personas fanáticas. Cuando estas personas se las ven con otras para debatir lo que hacen es repetir monótonamente sus posturas de fondo, aunque varíen sus argumentos y "pruebas" de respaldo. Pero eso sí: todo lo que se esgrima como argumento o prueba adicional está orientado a confirmar el planteamiento invariable que el fanático (o la fanática) han convertido en su causa. De aquí que, desde una postura fanática, lo que menos se hace es escuchar a los demás; se sabe, de antemano, que están en el error, por lo cual lo que digan no tiene ningún valor, salvo el de pretender "malvadamente" socavar la "verdad" que el fanático posee y que éste no tiene más remedio que proclamar una y otra vez, por todos los medios posibles, hasta que los demás acepten su equivocación o por lo menos se queden callados.

En tercer lugar, el fanatismo es, de manera obsesiva, monotemático. Los nervios, el cuerpo, la inteligencia y la voluntad del fanático están volcados, 
plenamente, a la causa que se ha asumido. El ser del fanático se revela violentamente ante los "enemigos" de su causa (que son todos aquellos que no la hacen suya de manera incondicional). Cualquier argumentación, valoración o prueba que no refuerce la tesis de fondo del fanático es vista como una afrenta intolerable, como expresión de la maldad más abyecta, como un atentado contra la "verdad" irrefutable poseída por él o ella.

Así, en cuarto lugar, además de monotemático y obsesivo, el fanático (o la fanática), es intolerante. Rechaza visceralmente opiniones, valores y pruebas contrarias a las suyas. Le gustan y celebra las que confirman su visión de la realidad, pero rechaza violentamente las que la contrarían. No tolera los matices ni la diversidad, pues entiende que, en el plano del conocimiento, lo que hay es "verdad" y "falsedad" (siendo la primera algo que le pertenece) $y$, en el plano moral, lo que hay es "bondad" (personas buenas) y "maldad" (personas malas), sin mezclas ni posturas intermedias.

En quinto lugar, el fanático suele ser incoherente en su discurso, y también en su práctica. Por lo primero, no es extraño que su discurso mezcle indebidamente argumentos y "pruebas" de la más distinta procedencia, sin rigor y consistencia. No es extraño que mezcle algunas afirmaciones o hechos de la ciencia con aspectos de alguna doctrina ética, de alguna filosofía particular o de alguna religión, que ad hoc le sirvan para respaldar su postura acerca de un tema particular.

En esta línea, el fanático gusta de grandes formulaciones (abstractas a más no poder), pero no atiende a sus implicaciones reales, que muchas veces ponen en tela de juicio la gran formulación que se defiende. Sobre todo, al proclamar grandes formulaciones (abstractas) el fanático se olvida (o pasa por encima) de las personas concretas, de carne y hueso, a la cuales el fanático no duda en sacrificar con tal de imponer su visión de la realidad. Asimismo, en lo que concierne a su práctica, no es inusual que el fanático contradiga con sus actitudes y comportamientos aquello que proclama discursivamente con furia.

En sexto lugar, la persona fanática, en su afán de mezclar cosas para defender su postura, violenta el carácter de aquello que usa para sostener o probar su visión de la realidad. Ya mencionamos que, por ejemplo, puede mezclar, sin orden y concierto, ciencia, con religión, filosofía y moral. Pero es que, además de eso, no es infrecuente que traicione la naturaleza de esos saberes.

En el caso de la ciencia, algunos fanatismos no entienden el significado de sus aportes teóricos y empíricos. Es que desde la ciencia -tanto natural como 
social- la verdad no se alcanza definitivamente; lo que la ciencia sostiene sobre la realidad natural o social son aproximaciones sujetas a revisión y a refutación. No son verdades definitivas lo que dice la biología, la química, la física, la astronomía o la sociología. Son, si se quiere, verdades provisionales. Su fortaleza es teórica y es empírica, pero eso no las convierte en verdades irrefutables o eternas.

Nadie puede ya ser una autoridad en el campo de la ciencia -dice Karl Popper-. Si alguien ha sido un gran experto, puede estar seguro que no lo seguirá siendo por mucho tiempo. Y la aceptación más o menos universal del carácter conjetural de la ciencia ha significado también un cambio fundamental en la actitud de los científicos con respecto a las refutaciones [...]. Nuestro conocimiento sólo puede ser conjetural, esto es, incierto y finito; nuestra ignorancia es necesariamente infinita. Ahora empezamos a conocer lo poco que sabemos: el desarrollo del conocimiento es lo que demuestra que Sócrates tenía razón. Estas verdades se han convertido en experiencias prácticas para la mayoría de los científicos².

La visión del conocimiento científico como una aproximación a la verdad no como una verdad definitiva- no es exclusiva de Popper. Por ejemplo, el astrónomo John Barrow sostiene que:

nuestro ritmo actual de descubrimiento de verdades sobre cosas en apariencia fundamentales no indica necesariamente que nos estemos acercando al lugar donde se encuentra enterrado el tesoro. El proceso de descubrimiento podría continuar indefinidamente, bien porque la complejidad de la naturaleza es en verdad insondable, o bien porque hemos elegido una forma particular de descripción de la naturaleza que, aun siendo tan exacta como deseemos, no es en el mejor de los casos más que una aproximación asintótica que podría llegar a corresponder exactamente a la realidad sólo mediante un número infinito de refinamientos. Con más pesimismo, nuestro contexto humano y su accidentado pasado evolutivo pueden poner límites reales a los conceptos que podemos aportar ${ }^{3}$.

Otras formas de conocimiento humano (como el teológico-religioso, el filosófico o el ético) son más débiles, teórica y empíricamente, que la ciencia. Son más

2 K. Popper, "De la tolerancia" (1981). En Después de la sociedad abierta. Buenos Aires, Paidós, 2010, pp. 404-405.

3 J. D. Barrow, Teorías del todo. Barcelona, Crítica, 1994, p. 12. 
conjeturales y especulativas. Tampoco ofrecen -hablando desde criterios seculares- verdad alguna sobre la realidad, sino discursos sobre presuntas verdades y realidades irrefutables. Lo cual es algo distinto a lo que hace la ciencia, pero no es algo superior ni mucho menos incontrovertible. Al contrario, cualquier asunto que se diga desde la filosofía, la ética o la teología es totalmente discutible y opinable, sobre todo si no hay pruebas concluyentes que permitan dirimir con una mediana seguridad los temas que esas disciplinas plantean.

Por tanto, cuando el fanático proclama que posee la "verdad" sobre un asunto y esgrime argumentos científicos en su favor lo que hace es violentar el carácter de la ciencia, que se ha construido mediante la aceptación de que nadie posee la verdad, mucho menos los científicos. Cuando un fanático defiende sus tesis tomando argumentos de determinada filosofía, de determinada religión o de determinada moral, y los presenta como "verdades" irrefutables no entiende que ninguno de esos argumentos es irrefutable, sino todo lo contrario: son, mucho más que las afirmaciones científicas (que tienen a su favor respaldos empíricos), argumentos discutibles y rebatibles por más que se refieran a cosas sublimes y maravillosas.

Mucho de lo anterior se aplica a algunas personas que, no sin una dosis importante de fanatismo, han hecho suya la causa (cruzada) del antiaborto en nuestro país. Ciertamente no a todas, pues no han faltado las voces de quienes, preocupados por el tema del aborto, y oponiéndose en principio al mismo, han estado dispuestos a dialogar con quienes discrepan de ellos y a encontrar, a partir de ese diálogo, salidas realistas a situaciones concretas de aborto.

\section{Individualidad humana: un planteamiento crítico y realista}

A continuación se plantea un conjunto de argumentos críticos orientados a colocar el tema de la individualidad humana (biológica, psicológica y social), de modo que se limpie el terreno de la maleza de los tabúes y el oscurantismo. En la mira, está el problema del aborto, pero también otros aspectos relacionados con la humanización y dignificación de las personas. Este planteamiento inicia con una crítica de los enunciados abstractos que se han puesto en circulación no sólo en nuestro país, sino en otros lugares. Luego se hará una aproximación a la realidad humana desde las ciencias naturales y sociales, para terminar con el enfoque de los derechos naturales y los derechos humanos. Se buscará apuntar, con la mayor claridad, la diferencia entre unos enfoques y otros, así como vinculación y potenciación recíproca. 


\subsection{Crítica de los enunciados abstractos}

Esta búsqueda de soluciones realista a situaciones concretas de aborto (aunque el criterio vale para otros problemas) debe iniciar con una actitud crítica ante enunciados abstractos cuya carga semántica oculta, por su enorme dosis de significado "trascendente", realidades diversas.

En el terreno que nos ocupa, hay quienes proclaman el lema "Sí a la vida", dando a entender por ello que lo suyo es la "defensa de la vida" en oposición a quienes están en "contra de la vida". Al oponerse al aborto, los primeros dan a entender que lo hacen porque están a favor de la vida, y sus rivales en el debate están en contra de ella. Esta forma de plantear las cosas es cuestionable desde los criterios de un debate racional. Veamos por qué.

La vida, como tal, no existe. Es una abstracción. Lo que existe en la realidad son seres vivos individuales (con capacidad autopoiética) en una diversidad que abarca, cuando menos, desde las amebas -pasando por todo tipo de formas vivientes unicelulares y pluricelulares - hasta los seres vivos superiores desde un punto de vista zoológico. En estos tramos superiores de la evolución animal estamos nosotros -los homo sapiens-, no como algo absolutamente excepcional sino como parte de una cadena evolutiva que nos emparenta con monos, gorilas y orangutanes.

Entonces, desde este punto de vista, "sí a la vida" (o su equivalente: defender la vida") supone una defensa (un sí) a toda la diversidad de las formas vivientes, lo cual incluye la defensa de cualquier tipo de organismo viviente, sin importar su impacto negativo o positivo para los organismos vivientes humanos.

Sin embargo, es seguro que quienes dicen "sí a la vida", para sostener sus posturas anti-aborto, no estarán de acuerdo con esta consecuencia lógica de su macro (y abstracto) enunciado. Seguramente dirán que lo suyo es una defensa de la vida humana, es decir, lo de ellos es un "sí a la vida humana". Si se les toma la palabra, ¿cuál es la consecuencia de ello?

Pues bien, la vida humana tampoco existe como tal. Lo que existe realmente es una diversidad de individuos ya nacidos, que viven en distintas condiciones y riesgos desde su nacimiento hasta su muerte. También existen los embriones de homo sapiens, en distintas fases de su gestación biológica, previa a su nacimiento. 0 sea que la vida humana se refiere a toda esta diversidad y quienes apuestan por la defensa de la vida humana deberían defender toda esa diversidad, amenazada por distintas circunstancias y condiciones. 
Pero, hasta donde se sabe, quienes defienden posturas anti-aborto (y dicen "sí a la vida" humana), no están interesados e interesadas en la defensa de la diversidad de individuos humanos ya nacidos ( $\mathrm{y}$ amenazados por guerras, pobreza, marginación y exclusión) ni tampoco en la defensa de todos los individuos en su desarrollo embrionario, cuyas madres viven en la pobreza y en la marginalidad.

Quienes asumen posturas anti-aborto, en realidad, tienen una preocupación concreta: les interesa defender a los vivientes humanos en su desarrollo embrionario, pero no en su totalidad, sino a aquella porción de ellos y ellas que se ve amenazada por prácticas abortivas. No les interesa la defensa de la diversidad biológica -como dice el lema "sí a la vida"- ni tampoco la defensa de la diversidad de individuos humanos nacidos o por nacer. Sólo aquellos de estos últimos que corren el riesgo de ser abortados mediante prácticas orientadas a ese fin.

Cuando se fija como tema de debate este último aspecto, la discusión gana en concreción y pierde esa aura mística y abstracta (malévola o bondadosa) que tiene cuando se aborda el asunto como una pugna entre quienes, supuestamente, defienden la vida y quienes la atacan. Una primera conclusión que puede sacarse en limpio es que no por estar a favor del aborto se está en contra de la diversidad de la vida animal y humana ni por estar en contra del aborto se está a favor de esta última. E incluso puede suceder lo contrario: quienes están en contra del aborto (y de las prácticas que se realizan para tal fin) bien pueden ser contrarios a la diversidad de la vida animal y humana (o por lo menos esta les puede ser indiferente) y, a la inversa, quienes están a favor del aborto (y de todas o algunas prácticas que lo facilitan) pueden estar a favor de la diversidad biológica (animal y humana).

Una vez clarificado el tema objeto de controversia, lo más atinado para un debate racional y crítico es tener en cuenta que las ciencias biológicas, especialmente la embriología, aportan conocimientos sobre el desarrollo biológico de los homo sapiens en su gestación y maduración en el vientre materno. Sin los conocimientos biológicos mínimos difícilmente se saldrá del oscurantismo y los tabúes relativos a la realidad humana. Los tabúes y el oscurantismo siempre son fuente de hábitos sociales perniciosos para las personas que se ven atrapados en ellos. Fomentarlos es una grave irresponsabilidad social.

\subsection{Aportes de la biología}

Hay varias cosas que se saben, tanto sobre la maduración en días, semanas y meses del nuevo ser, así como de su vínculo con su madre. Se sabe que, a medida que pasa el tiempo y la formación del nuevo ser se va completando 
hasta estar listo para ver la luz, éste tiene una relación de interdependencia con su madre. Va ganando independencia biológica ${ }^{4}$-esta es una condición para que exista un organismo viviente-, pero esa independencia no es total mientras está en el cuerpo de la madre, de la cual depende principalmente para su nutrición. Las expresiones usadas por algunos biólogos son "simbiosis de dos vidas" o "convivencia de dos vidas", lo cual quiere decir que "desde el primer día de vida se desarrolla un diálogo molecular entre el embrión y la madre [...], la gestación se convierte así en una convivencia de dos vidas: el hijo no es una parte de la madre ni tampoco un injerto que sería rechazado [...]. La dependencia de la relación con la madre no supone carencia de autonomía como individuo" 5 .

El nuevo ser no es uno con la madre, como no lo son parásitos como las lombrices, las amebas, los virus o las bacterias. Pero fuera del cuerpo de la madre, cuando biológicamente todavía no le ha llegado su tiempo, tendría severas dificultades naturales para vivir. Más aun, una vez nacido el individuo humano, como ser biológico, todavía no ha completado su maduración neuronal. Por lo tanto, el vínculo con la madre (o con su equivalente) sigue siendo crucial en los primeros años, y luego la acogida que le da la sociedad -y los aprendizajes sociales, comenzando con el lenguaje - ayudan a completar la maduración biológica del nuevo ser ${ }^{6}$. Desde las neurociencias,

existe un periodo crítico del desarrollo en el que tanto las conexiones neuronales como la experiencia deben interactuar para asegurar el desarrollo apropiado del sistema [...]. Un hecho establecido es que nuestros genes, que se expresan en cada una de nuestras células nerviosas, nos determinan, pero es también un hecho establecido que la experiencia y la educación en el curso de la vida nos individualizan mediante la afinación del patrón de conexiones neurales subyacentes a la función del cerebro. Al momento del nacimiento no estamos dotados de una máquina terminal, sino adaptados para el desarrollo en direcciones individuales; cada persona es única ${ }^{7}$.

\footnotetext{
4 Los biólogos llaman a esta independencia "autopoiesis", tal como la definió Humberto Maturana. "La noción de autopoiesis sirve para describir un fenómeno radicalmente circular: las moléculas orgánicas forman redes de reacciones que producen a las mismas moléculas de las que están integradas. Tales redes e interacciones moleculares que se producen a sí mismas u especifican sus propios límites son los seres vivos. Los seres vivos, entonces, quedan definidos como aquellos cuya característica es que se producen a sí mismos, lo que se indica al designar la organización que los define, como autopoiética". Darío Rodríguez M., Javier Torres N., "Autopoiesis, la unidad de una diferencia: Luhmann y Maturana”. Sociología, Porto Alegre, años 5, No. 9, jan/jun 2003, p. 113.

5 Natalia López Moratalla, Esteban Santiago, Gonzalo Herranz Rodríguez, "Inicio de la vida de cada ser humano. ¿Qué hace humano el cuerpo del hombre?”. Cuaderno de Bioética, XXII, 2011, 2, pp. 298-299.

6 Cfr., Henri Wallon, La evolución psicológica del niño. México, Grijalbo, 1977.

7 Ramón de la Fuente, "Las bases neurológicas de la mente". En Ramón de la Fuente et al., Biología de la mente. México, FCE, 1998, pp. 17-20.
} 
Asimismo, el vínculo biológico de la madre con su hijo (o hija) mientras este se forma en el vientre materno constituye una experiencia que cada madre vive de manera particular, siendo sumamente difícil que dos madres vivan de la misma manera su embarazo, y siendo imposible que una persona no embarazada pueda hablar en nombre de la que sí lo está -de sus sensaciones, sentimientos, bienestar o malestar- porque, como sucede con las enfermedades, cada mujer embarazada vive su condición de un modo bien propio, es decir, irremplazable.

Por otro lado, como sostienen biólogos respetados, y muy humanistas, los seres humanos no somos extraordinarios desde un punto de vista biológico sino bastante incompetentes y débiles. Tardamos bastante en estar a punto, listos para vivir por nuestra cuenta, y además somos sumamente "inespecializados" en el mecanismo que es vital para la sobrevivencia: el mecanismo estímulorespuesta, que en nosotros no es firme ni automático como en otras especies animales.

El cerebro animal funciona tan perfectamente que es capaz de ajustar muy bien la respuesta a los estímulos dirigidos a aquellas necesidades biológicas de las que depende la supervivencia del individuo y de la especie. Alcanzan así una tal especialización a los que les conviene para sobrevivir, que las especies tienen su propio nicho ecológico donde tienen cubiertas todas las necesidades. El animal está de esta forma encerrado, especializado, en el espacio vital de su nicho ecológico, y en el presente, puesto que los estímulos -desencadenantes de una respuesta en tanto tienen significación biológica- provocan comportamientos que son específicos y automáticos ${ }^{8}$.

¿Y el ser humano?

El actuar del hombre pone de manifiesto, hasta el nivel más pegado a la biología, que no está estrictamente sometido a las condiciones materiales. En primer lugar, no tiene un conjunto fijo de estímulos, sino que puede interesarse por cosas que incluso no existen. Una vez aceptado el estímulo, puede reaccionar de formas diversas, no determinadas biológicamente, a veces culturales y a veces 'contraculturalmente', e incluso no reaccionar. Además, no se pone automáticamente la respuesta, cuando se dan acontecimientos biológicamente significativos; 0 , si se pone, puede liberarse de este automatismo. Podemos decir que cada hombre afloja las ligaduras que 
lo atan a los genes: los nudos gordianos. La conducta humana no sólo no es instintiva ni automática sino que además humaniza las tendencias naturales necesarias?.

Lo anterior es algo básico en conocimientos biológicos. Es preciso recordarlo para evitar esas visiones que pretenden hacer de los seres humanos los reyes de la evolución biológica o algo semejante. Nuestro lugar es modesto y nada extraordinario o especial. Somos, como dejó establecido Darwin de una vez por todas, "una especie más que evolucionó por selección natural cuya única singularidad es que alcanzó la llama de la inteligencia o, si se quiere, conciencia, que no es más que conocimiento de sí mismo ${ }^{10}$ " y que las neurociencias y ciencias sociales, como la antropología, la psicología y la sociología, explican sin recurrir a conjeturas metafísicas, místicas o religiosas.

En fin, como sostienen algunos biólogos y paleontólogos, la aparición de los individuos humanos, como seres vivos, es un "simple resultado fortuito, resultado de miles de acontecimientos enlazados, cada uno de los cuales, además, podría haber tenido lugar de manera diferente y haber dirigido la historia una senda alternativa diferente, que no hubiera conducido al hombre" 11 . Hay serías dudas, en el mundo científico, sobre un diseño inteligente que necesariamente pondría a la especie humana sobre la tierra para que ésta reinara por encima de todo lo demás. Para alguien como Stephen Jay Gould, la especie humana es un fenómeno menor en la evolución animal,

que surge como secuela lateral de un punto de partida físicamente limitado. La característica más notable de la vida ha sido la estabilidad de su modo bacteriano desde el inicio del registro fósil hasta nuestros días; rasgo que, además, perdurará mientras la tierra aguante. Estamos en la Edad de las bacterias. Lo fue en el principio y lo será por siempre ${ }^{12}$.

Como quiera que sea, además de no ser la coronación del proceso evolutivo, somos pobres biológicamente. "El cuerpo del hombre muestra rasgos morfológicos y funcionales muy peculiares, todos ellos ligados al peculiar cerebro humano, que ponen de manifiesto la pobreza biológica que le caracteriza"13. Pero eso que en el plano biológico es debilidad, es una fuente de posibilidades para Ariadna. Diez descubrimientos científicos que cambiaron la visión del mundo. México, Debate, 2008, p. 354.

11 José Manuel Nieves, Hablemos de ciencia. Madrid, EDAF, 2006, p. 248.

12 Stephen Jay Goould, citado por José Manuel Nieves en Ibíd., p. 248.

13 Natalia López Moratalla, et al., Ibíd., p. 301. 
abrirse a una vida no amarrada a los automatismos biológicos, es decir, la vida en sociedad: “lo genuinamente humano de cada hombre aparece como un conjunto de capacidades, específicas todas ellas y debidas a su liberación del automatismo biológico"14. Todo comienza con la necesidad de completar la maduración neuronal con los otros:

el desarrollo psicofísico, el aprendizaje, etc., requieren un ámbito de relaciones personales de textura familiar, sin el que el niño sufra retrasos en su maduración intelectual y personal. No se inicia el desarrollo de la corteza cerebral, ni se distribuyen las funciones en los dos hemisferios propios del cerebro humano si no llegan, en edad temprana, las conexiones que el sistema límbico emite hacia la corteza al 'procesar' las emociones [...]. Las características del cerebro humano aportan el presupuesto biológico a un viviente, que requiere relación personal y sentido de vida para su desarrollo natural ${ }^{15}$.

Sabemos, desde la biología en sus diversas ramas, bastantes cosas sobre el desarrollo embrionario de los individuos humanos. Se conocen las condiciones orgánicas, anatómicas, fisiológicas, endocrinas, etc., que debe cumplir el nuevo ser en formación para estar preparado, desde un punto de vista biológico, para nacer y poder continuar su maduración una vez nacido.

La biología molecular y la genética han aportado conocimientos importantes acerca del desarrollo normal de los embriones humanos, así como de las anomalías que se pueden dar en ese proceso. Anomalías, de mayor o menor gravedad, que pueden ser de carácter genético u obedecer a influencias del entorno (nutricionales, sanitarias, químicas, etc.). Incluso se ha avanzado en el diagnóstico de anomalías (genéticas principalmente) que pueden afectar el desarrollo posterior del nuevo individuo una vez que ha nacido. De tal suerte que las ciencias biológicas han aportado conocimientos valiosos para la medicina y ésta tiene enormes capacidades (aunque no ilimitadas) para intervenir, con cuidos de diverso tipo, en el desarrollo favorable de los embriones humanos y para tratar de corregir algunas de las anomalías que se generan en su desarrollo en el vientre materno, y también después de nacidos.

Ahora bien, desde la biología, como ciencia natural, no es posible pronunciarse sobre la dignidad o humanidad del ser humano en su desarrollo embrionario ni en su desarrollo una vez que ha visto la luz. No es que muchos biólogos no 
tengan una postura sobre ese tema (o sobre temas religiosos, por ejemplo), pero desde el saber biológico no cabe un veredicto sobre la humanidad/dignidad de los individuos humanos.

Para el conocimiento de su desarrollo embrionario, normal o anormal, bastan y sobran los criterios que se usan para estudiar a otros primates superiores, con los cuales dicho sea de paso se han anticipado muchas indagaciones sobre la biología humana. Cuando se examina la influencia del entorno sobre los embriones humanos, a través de la nutrición, la salubridad o las drogas, se siguen los criterios de la química y la física, lo mismo que se haría, en iguales condiciones, con animales superiores sometidos a las mismas influencias.

\subsection{Biología + ciencias sociales}

Una vez nacido, cada individuo humano sigue su propia trayectoria biológica hasta su muerte. Las ciencias biológicas aportan conocimientos valiosos sobre esa trayectoria, sus dinamismos y deterioro, cuando la entropía hace de las suyas. Pero, después de ver la luz, la trayectoria del individuo recién nacido ya no está marcada sólo por su realidad biológica, sino que recibe una nueva marca: la marca social que en un tramo importante de la vida del recién nacido es crucial para que este complete su maduración biológica en su dimensión neuronal. Es decir, el desarrollo neuronal humano requiere de la impronta social, principalmente, a través del lenguaje, para llegar a feliz término. Las neurociencias estudian, hoy por hoy, este apasionante tema.

Pero si las neurociencias son una de las fronteras de la biología para entender al ser humano como ser natural, la presencia de lo social en la vida de ese ser ${ }^{16}$, y la forma cómo lo social interviene en su desarrollo no sólo biológico, sino como un ser que se relaciona con otros simbólicamente (mediante el lenguaje), que crea cultura, que trabaja, que tiene una identidad individual y colectiva, que piensa sobre sí mismo, que reflexiona, que genera conocimiento científico, etc., todo eso escapa a la biología y hace necesaria la intervención de las ciencias sociales (desde la psicología, pasando por la economía y la política, hasta la antropología y la sociología).

Las ciencias sociales aportan conocimientos importantes sobre los individuos humanos no sólo como realidades biológicas, sino como realidades bio-psicosociales. Desde estas ciencias, el individuo humano, desde que ve la luz, comienza un recorrido en el cual los condicionantes socio-culturales serán decisivos para su realización, completa o incompleta, como ser humano. Una 
condición esencial para ello, como enseñan la antropología y la psicología, es la adquisición del lenguaje, que es imprescindible para el desarrollo mental del individuo. Sin ese desarrollo mental mediante el lenguaje, además de verse afectada la maduración neuronal (como enseñan las neurociencias y la neuropsicología) es imposible que el individuo llegue a tener la vida mental reflexiva y autoconsciente que son características propias de lo humano ${ }^{17}$.

"Sea como sea -escribe Robin Dunbar- los humanos nos diferenciamos de todas las especies animales -incluyendo nuestros primos, los simiospor una cuestión obvia: el lenguaje. Hay cerca de cuatro mil especies de mamíferos, y casi diez mil especies de pájaros (...) pero somos la única que tiene esa capacidad. Por supuesto que las demás especies se comunican, a veces de maneras sorprendentemente sofisticadas, pero ninguno de sus sistemas de comunicación puede igualar el lenguaje humano en flexibilidad y capacidad para transmitir información [...]. El lenguaje, en definitiva, nos permite mantenernos al día sobre lo que pasa en el mundo siempre cambiante de nuestras relaciones sociales"18.

Desde el punto de vista de las ciencias sociales, el individuo humano se realiza en su vinculación social y cultural con otros. Es decir, la humanidad no es algo que se trae los genes, sino algo que se conquista (o se pierde) en la vida social, que es también histórica. La humanidad del individuo humano no está en su biología, aunque sin su biología no sería posible, sino que es algo que se construye, que se va ganando (o perdiendo) según sean las condiciones sociales (culturales, económicas) en la que cada individuo humano realiza su vida.

Así como la biología como tal no puede pronunciarse sobre la humanidad de un embrión de homo sapiens (o sobre su dignidad) tampoco lo pueden hacer las ciencias sociales -al menos, en el estado actual de los conocimientos en ambos campos de la ciencia-. Al contrario, las indagaciones realizadas desde las ciencias sociales permiten sostener fuertes dudas sobre la humanidad (o dignidad) plena de un embrión humano e incluso de millones de individuos humanos ya nacidos cuyas condiciones de vida los deshumanizan y niegan su dignidad. O sea, desde las ciencias sociales la dignidad y humanidad no se tienen por razones biológicas, sino que se adquieren (o no) en la trayectoria de vida (social-cultural) de cada cual.

17 Cfr., Alberto L. Merani, El lenguaje. México, Grijalbo, 1979.

18 R. Dunbar, La odisea de la humanidad. Una nueva historia de la evolución del hombre. Barcelona, Crítica, 2007, pp. 110- 117. 
No se trata de dones biológicos, sino atributos que tienen que ser conquistados social e históricamente. 0 sea que, desde las ciencias sociales, es muy fuerte la evidencia de que la humanidad y la dignidad es algo que los individuos (homo sapiens) conquistan (o no) a lo largo de su trayectoria vital, desde el nacimiento hasta su muerte, viviendo en sociedad. Su integralidad biológica -su correcto desarrollo orgánico, anatómico, fisiológico, neuronal- es crucial para ello pues no sólo el cuerpo biológico los acompañará mientras vivan, sino que es uno de los soportes fundamentales de la humanización, comenzando con su completa maduración neuronal ${ }^{19}$. La humanidad y dignidad que el homo sapiens pueda alcanzar comienza con su integralidad biológica, con la plenitud de su desarrollo biológico, de tal suerte que determinadas alteraciones biológicas -sucedidas en la etapa embrionaria o una vez nacido- pueden constituir -si su alcance llega hasta las estructuras biológicas del homo sapiens- una seria amenaza para su humanización.

Lo mismo dígase de las amenazas sociales, económicas y culturales que se pueden desatar sobre los homo sapiens ya sea en su fase embrionaria (siendo sus madres las afectadas directamente) o ya sea una vez nacidos, en su trayectoria de vida en sociedad. La integralidad biológica de los seres humanos, pues, es necesaria para que puedan realizarse en su humanidad y dignidad, pero no suficiente: unas condiciones sociales y culturales óptimas son el otro factor clave. Si unas y otras faltan (sobre todo si faltan las segundas, como suele suceder), caben serias dudas acerca de las posibilidades de humanización y dignificación efectivas de los homo sapiens. "Inseparablemente, cada vida humana es la vida de un sujeto que es corporal, biológico, y que a la vez es personal a lo largo de la trayectoria temporal de crecer, madurar, envejecer y morir" ${ }^{20}$. Ya fue dicho: el individuo humano es una realidad bio-psico-social, es decir, su comprensión no puede reducirse a un

análisis de factores biológicos, sociológicos o histórico culturales tomados fragmentariamente. El hombre vive en interdependencia con los demás hombres, con todos sus antepasados y contemporáneos, elaborando desde el nacimiento hasta la muerte nuevas uniones condicionales sobre las que asienta primero el desarrollo y después la actividad del sistema nervioso superior, que involucra la función social porque su actividad únicamente cobra sentido cuando se ejercita en el medio propio del hombre: la sociedad ${ }^{21}$.

19 Cfr., Alexander R. Luria, El cerebro humano y los procesos psíquicos. Barcelona, Fontanella, 1979.

20 Natalia López Moratalla, et al., Ibíd., p. 285.

21 Cfr., Alberto L. Merani, Psicología genética. México, Grijalbo, 1982, p. 25. 


\subsection{La consideración de derechos naturales y los derechos humanos}

¿Entonces las ciencias sociales están en contra de los derechos humanos de los individuos humanos en embrión o ya nacidos? No, de ninguna manera. Es que como saben los especialistas en derechos humanos, estos comprenden lo que se "debe" (según el marco filosófico y ético que así lo prescribe) a los seres humanos, no lo que estos efectivamente son o poseen. En realidad, muchos de los derechos (de lo que se debe) a los seres humanos por ser tales no tienen vigencia de hecho, y la proclama y defensa de los derechos humanos es una crítica a esa situación de negación de los mismos.

Conviene citar aquí a Norberto Bobbio, quien comenta de este modo la afirmación de la Declaración Universal de los Derechos Humanos que dice: "todos los seres humanos nacen libres e iguales en dignidad y derechos".

Quien lea distraída y superficialmente -escribe Bobbio- las palabras de la Declaración universal [...] le parecerán no sólo conocidas sino incluso obvias. Pero ¿son realmente tan evidentes? Si consideramos la redacción desde un punto de vista literal, contienen una afirmación que, para empezar, no es cierta porque no todos los seres nacen libres e iguales. No nacen libres, pese a la opinión de Rousseau, sino más 'encadenados' de lo que nunca estarán desde su nacimiento; tampoco son iguales, ni siquiera en dotes naturales, por no hablar de las condiciones sociales e históricas. Pero no debemos tomar la redacción al pie de la letra, sino interpretarla. $Y$ una vez interpretada, se percibe que no es tan obvia. Que los seres humanos nazcan libres e iguales quiere decir en realidad que deben ser tratados como si fueran iguales y libres. La redacción no describe un hecho, trata de prescribir un deber. ¿Cómo puede convertirse esa descripción en una prescripción? Dándonos cuenta de que afirmar que los seres humanos nacen libres e iguales quiere decir en realidad que nacen libres e iguales por naturaleza, es decir, según su naturaleza ideal, elevada a criterio supremo para distinguir lo que se debe hacer de lo que no se debe hacer. En otras palabras, podríamos decir que la libertad y la igualdad de las que se habla en aquel artículo no son un hecho sino un derecho, y más concretamente el derecho que deriva de ser humano, antes aún que de una constitución positiva, de la constitución misma de la personalidad; una vez más, de la naturaleza ideal. Como se ve, también por este camino llegamos a la doctrina de los derechos naturales ${ }^{22}$

22 Norberto Bobbio, "La declaración universal de los derechos del hombre". En Teoría general de la política. Madrid, Trotta, 2009, pp. 522-523. 
Pero las ciencias sociales y naturales no tratan del "deber ser", sino de lo que "es". Si no se conoce cómo son las cosas, y se insiste en cómo deberían ser, se cae en la discusión de juicios de valor, que es un terreno en el cual prácticamente todas las opiniones cuentan por igual o, cuando menos, no hay una que pueda darse por definitiva y concluyente.

En este punto, es preciso hacer una consideración sobre el carácter de las argumentaciones éticas, filosóficas y religiosas. Se trata de argumentaciones no científicas, en el sentido que no reúnen los requisitos teóricos y empíricos propios de las ciencias. Esto hace que sean fuertemente conjeturales y en algunos casos fuertemente especulativas.

Asimismo, son fuertemente valorativas y prescriptivas, no descriptivas ni explicativas. Un argumento filosófico, ético o religioso, aunque apunta a cosas que a muchos les parecen correctas y "verdaderas", es probable que, a otros muchos, les parezcan incorrectas y falsas, y no es legítimo, en un marco democrático, que los primeros quieran imponerlo a los demás como si fuera el único punto de vista válido. En el terreno, filosófico, ético o religioso la controversia y la diversidad de puntos de vista es inevitable y la tolerancia es necesaria.

Para lograr una correcta racionalidad en el debate, por un lado, deben colocarse las argumentaciones de carácter científico (natural y social), por otro las argumentaciones filosóficas y éticas, y por otro las religiosas. Al mezclarlas se puede incurrir en falacias y además generar confusión. También es falaz atribuir características de un tipo de argumentación a otra, por ejemplo, atribuir a una formulación científica características (o implicaciones) de una formulación filosófica, ética o religiosa.

Hay quienes desconocen que al campo ético-normativo pertenecen la doctrina de los derechos naturales de los individuos y todas las formulaciones de derechos humanos derivadas de esta y la doctrina del contrato social. De esta última cabe decir que es una ficción: no es cierto, desde criterios históricos y sociológicos, que los individuos humanos vivieran, antes de que existiera la sociedad, en un estado de naturaleza de guerra de todos contra todos (o de idilio salvaje) y que luego acordaran crear, mediante un pacto (un contrato social), un orden social y depositar el poder de mantenerlo en el Estado (o en el Leviatán, como decía Thomas Hobbes). Pese a que esta formulación es una ficción, ha sido una ficción que ha influido en la construcción de los ordenamientos jurídicos modernos occidentales. Es una ficción útil; y no es la primera ni ha sido ni será la última. 
Sobre la doctrina de los derechos naturales, se trata de una construcción que articula aspectos filosóficos del llamado iusnaturalismo con aspectos de la tradición cristiana que se secularizan, precisamente, con la doctrina de los derechos naturales. Norberto Bobbio es de gran ayuda para clarificar este asunto:

cuando hablo de la doctrina de los derechos naturales me refiero a algo distinto a la doctrina del derecho natural. En estas expresiones el término derecho se toma bien en sentido subjetivo, como facultad o poder, bien en sentido objetivo, como norma de conducta. Si la doctrina del derecho natural es tan antigua como la filosofía occidental, la doctrina de los derechos naturales, fundamentos de las famosas declaraciones [de derechos humanos], es moderna. La auténtica doctrina de los derechos naturales aparece por primera vez en los autores del siglo XVII, comenzando por Hobbes y su célebre distinción entre lex, entendida como fuente de obligaciones, y ius, entendido como libertad de toda obligación. Bien mirado, sin embargo, el paso tradicional del derecho natural a la doctrina moderna de los derechos naturales se produce dentro del sistema iusnaturalista, y es un paso rico en consecuencias [...] el iusnaturalismo ha desempeñado la función histórica permanente y fundamental, la de establecer límites al poder del Estado. Ahora bien, la teoría de los derechos naturales, que se consolida con el iusnaturalismo moderno, representa la confirmación de los límites del poder estatal, considerados no ya desde el punto de vista exclusivo de los gobernantes, sino también desde el punto vista de los derechos de los gobernados ${ }^{23}$.

Es esa la raíz de las declaraciones de los derechos humanos, en sus diversas concreciones y especificaciones. Los derechos humanos de los gobernados lo que se debe a ellos y ellas en razón de su naturaleza ideal- deben ser protegidos no sólo por el Estado, sino contra el Estado. En palabras de Bobbio:

los derechos naturales, reconocidos ya por la Asamblea General de las Naciones Unidas, es decir, por el más alto órgano representativo de la comunidad internacional, tienden a ser protegidos no sólo en el ámbito del Estado, sino contra el Estado mismo, es decir, tienden a una protección que podríamos llamar de segundo grado y que debería entrar en funcionamiento siempre que el Estado desatendiese sus obligaciones constitucionales hacia los ciudadanos ${ }^{24}$. 
Para concluir con Bobbio:

en otras palabras, mientras la afirmación de los derechos naturales era una teoría filosófica, esta tenía un valor universal pero ninguna eficacia práctica; cuando las constituciones modernas incorporaron los derechos, la protección de éstos se hizo eficaz, pero sólo dentro de las fronteras de aquél Estado que los reconocía. Después de la Declaración universal, la protección de los derechos naturales puede tener al mismo tiempo eficacia jurídica y valor universal. $Y$ el individuo tiende a pasar de sujeto de una comunidad estatal a sujeto también de una comunidad internacional, potencialmente universal ${ }^{25}$.

Queda claro, por todo lo dicho, que la doctrina de los derechos naturales, y su incidencia en las disposiciones en torno a los derechos humanos (o en las disposiciones constitucionales que las integran) no tienen una finalidad descriptiva o explicativa, como la tienen las ciencias naturales o sociales, sino una finalidad valorativa, prescriptiva y normativa.

No son una aproximación a la verdad de las cosas naturales y sociales -al modo cómo estas se comportan, funcionan, evolucionan o cambian-, sino que ofrecen un marco de creencias que se han revelado útiles y eficaces para regular la vida social y para proteger a los más débiles de los abusos de los poderosos. Quienes aceptan esas creencias (u otras: por ejemplo, que en lugar de derechos naturales los individuos tienen derechos divinos) pueden estar seguros de la "verdad" de sus creencias, pero no se trata de un criterio de verdad científica, pues la "verdad" científica es una verdad no sólo provisional, sino sostenida por teorías lógicas y rigurosas, y pruebas empíricas.

En resumen, las argumentaciones o formulaciones científicas nos permiten explicar o describir cómo funcionan, cambian, evolucionan, etc., los fenómenos naturales o sociales. Lo que la ciencia dice sobre esos fenómenos, aunque está respaldado por datos empíricos, siempre está abierto a la refutación. Se trata de conjeturas, de hipótesis avaladas por distintos tipos de pruebas, siempre sujetas a revisión. Son, como dice Karl Popper, una aproximación a la verdad de la realidad.

Hay otro tipo de formulaciones, filosóficas por ejemplo, que carecen del rigor lógico de las teorías científicas y de una base empírica. Pueden tratar de asuntos importantes para la vida humana -por ejemplo, dar orientaciones para llevar 
una vida prudente o recta- pero no suelen referirse a fenómenos (naturales o sociales) de los cuales se pueda tener un procedimiento de refutación o verificación.

Están también las argumentaciones de tipo religioso que no se cuidan del rigor lógico del lenguaje que usan ni les preocupan las pruebas que refuten sus planteamientos. Las formulaciones religiosas son inmunes a la refutación, de tal suerte que el único camino es aceptarlas sin discusión. Que sean irrefutables y poco rigurosas en su lenguaje no quiere decir que, algunas filosofías y religiones, no sean importantes para la vida humana, para las creencias, los valores y normas sociales. Pero eso lo que indica es que su importancia no es cognoscitiva (no están hechas para que los individuos conozcan la realidad), sino prescriptiva y normativa: favorecen ciertas conductas y dan sentido a la vida humana.

A este rubro pertenecen, precisamente, la doctrina de los derechos naturales, las declaraciones de derechos humanos y el contractualismo. Lo mismo podemos decir de los textos constitucionales modernos (inspirados en la revolución norteamericana, la revolución francesa, el republicanismo y el liberalismo). Usarlos como argumento para explicar/describir un fenómeno natural o social -como si lo que ahí se dice fueran definiciones científicas- es un despropósito mayúsculo que confunde y manipula a los ciudadanos y ciudadanas.

Los derechos humanos no niegan (ni están en contra de) los hechos humanos naturales y sociales (que las ciencias naturales y sociales nos ayudan a explicar/ describir/comprender), y si estos últimos se quieren adecuar a un deber ser-al deber ser de los derechos humanos- no queda más remedio -sino se quiere caer en idealismos imprácticos- que recocerlos como lo que son en su realidad fáctica.

\subsection{Ciencia, derechos naturales y derechos humanos}

Un asunto que no puede soslayarse tiene que ver con las relaciones existentes entre las ciencias naturales y sociales, y la doctrina de los derechos naturales y las declaraciones de derechos humanos. En el plano cognoscitivo, no suelen haber tensiones una vez que se reconoce el ámbito en el que mueven unas y otras. Las ciencias buscan conocer; la doctrina de los derechos naturales y las declaraciones de derechos humanos buscan establecer valores y normas conforme a un deber ser. Las unas son descriptivas/explicativas, las otras son normativas/valorativas. En las sociedades modernas hay una conciencia clara de esta distinción. También hay una conciencia cada vez más clara de que las formulaciones sobre los derechos naturales y las declaraciones de 
derechos humanos no deben entrar en disputa con las ciencias en materia de conocimiento, ni negar (o rechazar) lo que estas aportan como explicación/ descripción de los fenómenos naturales y sociales.

En el caso de los seres humanos, lo que se debe a éstos -según la doctrina de los derechos naturales y las declaraciones de derechos humanos- no puede afirmarse ni defenderse prescindiendo de lo que ellos son. Los conocimientos científicos ayudan a hacer realizables (en la práctica) muchos derechos humanos; los anclan en la realidad y los corrigen de un excesivo idealismo.

En el ámbito práctico, por otra parte, se suelen dar fuertes tensiones entre las implicaciones/aplicaciones (tecnológicas, médicas, económicas, sociales, ambientales, militares) de algunas ciencias y las concepciones y exigencias de los derechos humanos. Estas concepciones/exigencias en materia de derechos humanos corrigen o sirven para criticar aquellas implicaciones/aplicaciones cuando son perniciosas para la vida humana y, en el límite, cuando la ponen en peligro. Aquí, el aporte de los derechos humanos a la ciencia es ético, no cognoscitivo. Pretende influir en algunas aplicaciones/implicaciones perniciosas de la ciencia, pero no corregir sus teorías, hipótesis o procedimientos experimentales, que poseen su propia lógica de corrección crítica (teórica y empírica).

\section{La integralidad biológica de los individuos y su defensa ética}

La integralidad biológica de los individuos humanos es crucial para su desarrollo pleno (humano) psicológico y social. 0 , dicho de otro modo, para su realización como personas plenas en humanidad y dignidad. Se entiende aquí por "integralidad biológica" el completo desarrollo orgánico, anatómico, fisiológico y neuronal de los individuos, lo cual inicia en la fecundación, se continúa en las distintas fases por las que atraviesa el embrión en el vientre materno y se completa una vez que este ha visto la luz, en un tramo temporal importante posterior al nacimiento. La integralidad biológica, así entendida, es una de las bases materiales de la humanización del individuo; es la base para una vida mental rica que, con el uso del lenguaje, supone el conocimiento del entorno, el conocimiento de sí mismo, la reflexión y la autoconciencia; y es la base posibilitadora de las interacciones sociales que no sólo permiten la convivencia con otros y otras (la vida social), sino la actividad productiva y la actividad creadora en todas sus manifestaciones.

Una fractura en la integralidad biológica de los individuos -tanto en sus fases embrionarias, como en su trayectoria posterior al nacimiento- puede comprometer seriamente -si afecta las estructuras biológicas fundamentales- 
las posibilidades de su desarrollo humano pleno. A menos que se sostenga que la humanidad y la dignidad son una esencia que flota en el aire y que está más allá de lo material, no es concebible hacer del cuerpo (biológico) de los individuos algo irrelevante para la conquista de la humanidad y la dignidad.

Pero no del cuerpo (biológico) en cualquier condición, sino en una condición óptima desde el punto de vista orgánico, anatómico, fisiológico y neuronal, pues este es el punto de partida para la realización de los individuos humanos como realidades bio-psico-sociales.

Las fracturas (malformaciones, desarrollo orgánico, anatómico o neuronal incompleto) en la integralidad biológica de los individuos en las fases embrionarias pueden obedecer a factores genéticos (debidos a errores en el proceso de reproducción celular, por ejemplo) o a factores del entorno (nutrición o reacciones químicas/biológicas de la madre o accidentes, por ejemplo). Pueden ser de menor o mayor envergadura, según sea su impacto en las estructuras biológicas del embrión. Las ciencias biológicas y la medicina han avanzado extraordinariamente, por un lado, en la vigilancia y cuidados de los embriones sin mayores complicaciones en su desarrollo, al igual que en el cuido de sus madres (higiene, alimentación, etc.). También han avanzado notablemente en el diagnóstico, prevención y tratamiento de perturbaciones (ya sea genéticas, o provenientes del entorno) que puedan comprometer la integralidad biológica del nuevo individuo.

No obstante, en el mundo hay miles (y quizás millones) de embriones humanos -y sus madres- que no cuentan con los cuidos y la atención sanitaria y nutricional que les aseguren un desarrollo biológico integral, por lo cual al nacer tendrán serias dificultades para llevar una vida plena, por sus cuerpos dañados debido a la falta de nutrientes básicos. Otros miles de embriones sufren perturbaciones en su integralidad biológica debido a fallas genéticas, algunas de menor gravedad y otras más graves. Sin embargo, no reciben ninguna atención que ayude a corregir el daño -cuando ese daño es corregible- o a paliarlo, de tal forma que después nacer esos individuos tendrán una vida sumamente dura y difícil o, en muchos casos, su destino será una muerte dolorosa en el corto plazo.

En situaciones absolutamente extremas, su nacimiento no sólo compromete su propia vida -es decir, corren el riesgo de nacer muertos-, sino el de su madre, que también se ve amenazada de morir en el parto. 
Dejando de lado por ahora esos casos extremos, en situaciones de precariedad socio-económica (y de inexistencia de mecanismos públicos de ayuda), miles y quizás millones de madres (y sus familiares cercanos, cuando los hay) tienen que asumir, por su cuenta y riesgo, la enorme carga que supone la crianza y cuidado de individuos que no pueden valerse por sí mismos y que en ocasiones requieren de atención médica y terapias caras y fuera del alcance de sus familias. Esto sume a la madre y parientes en una mayor precariedad y abandono, ya que, después de todo, el cuido, atención, protección, alimentación y educación de los hijos e hijas, en sociedades con débiles (o inexistentes) mecanismos de bienestar social, recaen principalmente sobre aquellos. Y, aun en sociedades con sólidos mecanismos de bienestar social, las madres siguen siendo las que más asumen la responsabilidad ante sus hijos e hijas. Para éstos, la falta de la madre suele resultar insustituible; y cuando padecen dolencias que afectan su integralidad biológica su abandono e indefensión, ante la ausencia de su madre, se vuelven extraordinarias.

Por tanto, la integralidad biológica de los individuos (humanos) no es algo que debe tomarse a la ligera. Es la condición material de sus derechos humanos; es, pues, lo primero que se debe a los individuos: se debe proteger la integralidad biológica de ellos y ellas tanto en su desarrollo embrionario como a lo largo de su trayectoria de vida, una vez que nacen hasta su muerte. Que se deba no quiere decir que se haga. Es que, como ya se dijo, hay miles y quizás millones de individuos que no tienen asegurada su integralidad biológica no sólo por factores genéticos, sino también ambientales (sociales, ambientales, nutritivos, etc.). Algunos de esos factores -principalmente genéticos- son incontrolables tanto en su incidencia como en las consecuencias (efectos) a lo largo de la vida del individuo.

Otros, la mayoría de los generados en el ambiente, sí pueden ser controlados en su incidencia o, cuando menos, en sus efectos posteriores. Para esto último, se requieren mecanismos sociales y de bienestar que anulen su influencia o que pueden paliar significativamente su impacto, mediante sistemas médicos, nutricionales y de cuido adecuados.

O sea que esta dimensión de la protección de la integralidad biológica humana depende de un ordenamiento social, económico, cultural, jurídico e institucional adecuado y por el cual se tiene que trabajar. Si no existe ese ordenamiento, con los mínimos de bienestar social, la integralidad biológica humana se verá fuertemente amenazada en su cuido y protección, y no sólo eso: ahí donde haya una vulneración (genética o ambiental) de la integralidad 
biológica del individuo quienes cargarán con las consecuencias y costos de esa vulneración serán el individuo, su madre y quienes forman el entorno cercano familiar cercano. De faltar la madre y los familiares, será el individuo el que, en condiciones de abandono y desprotección sobrevivirá como pueda -si nace y resiste los primeros años-, muchas veces a la intemperie y en la precariedad más absoluta.

De tal suerte que defender la integralidad biológica de los individuos humanos nacidos o por nacer no es cosa de sólo proclamas genéricas, sino que debe atender a las condiciones concretas que afectan a cada individuo concreto. Cada individuo concreto es una realidad cuya integralidad biológica es crucial para su humanización y dignificación. Y si importa la dignidad y humanidad de las personas, la integralidad biológica de cada cual debe protegerse porque sin ella su humanización y dignificación reales son prácticamente imposibles. Debe protegerse, eso sí, realmente; no genéricamente, sino en cada caso concreto, en cada individuo, porque como dice Ramón de la Fuente, "al momento del nacimiento no estamos dotados de una máquina terminal, sino adaptados para el desarrollo en direcciones individuales; cada persona es única"26.

Hay que volver al tema de la integralidad biológica de los embriones de homo sapiens. Es indiscutible que tiene que ser protegida, asegurada y, en caso de verse vulnerada (por factores genéticos o ambientales), hacer todo lo que se puede con los recursos científicos, médicos y sociales para corregir esa vulneración o para corregir sus efectos. Pero en esto no debe olvidarse la integralidad biológica de la madre que, en términos biológicos, psicológicos y sociales, puede verse seriamente afectada no sólo por la condición de su embrión, sino por los tratamientos científicos, médicos y sociales destinados al mismo.

Hay algunas situaciones en las cuales la integralidad biológica de un embrión humano se puede ver seriamente comprometida debido al efecto de factores genéticos o ambientales. Estas situaciones particulares requieren un tratamiento caso por caso, sin dejar de lado la relación particular (y la vivencia/experiencia particular) de cada madre con el nuevo ser que se desarrolla en su vientre.

Primera situación: el embrión se puede ver afectado gravemente, por factores genéticos o ambientales, en su desarrollo biológico integral, padeciendo malformaciones severas que no pueden ser corregidas (en las condiciones científicas y médicas con las que cuenta una sociedad determinada) y que 
no sólo acompañarán al individuo mientras viva, sino que serán un obstáculo insuperable para que este desarrolle sus capacidades mentales y sociales, y en consecuencia que pueda valerse por sí mismo para sobrevivir. O sea, será un ser que dependerá en extremo del cuido de los demás para poder vivir. Se puede asegurar su sobrevivencia biológica en el vientre materno, su nacimiento y su sobrevivencia biológica, con esas severas malformaciones, durante algunos o muchos años posteriores a su nacimiento. No se pueden garantizar socialmente (públicamente) los cuidados adecuados, de tal suerte que su madre, padre y parientes cercanos deberán asumir con sus propios recursos el cuido de ese individuo que no puede valerse por sí mismo para vivir. Si faltan la madre, el padre y los parientes, su destino (a falta de protección pública) será una vida inhumana en extremo, animalizada pero no tanto como la de otros animales, pues el deterioro biológico del individuo lo pondrá en una situación de indefensión casi absoluta. Esto no es especulación, pues en nuestro país hay individuos que, con un grave deterioro neuropsicológico padecido en su vida embrionaria, nacieron y han logrado sobrevivir, pero su humanidad no se puede dar por supuesta. El abandono y la violencia padecida por ellos y ellas -porque sus padres y parientes renunciaron a su cuido o porque fallecieron, y porque el Estado no asume su responsabilidad - ha acentuado la miseria de su vida y las posibilidades de corregir algunos de sus hábitos animalizados. Estos individuos viven, aun con sus carencias, como seres biológicos -desarrollando una capacidad de resistencia ante un entorno hostil (frío o húmedo; con lluvias violentas o sol inclemente; alimentándose de comida sucia, cuando la hay), pero sólo por simplismo se puede decir que viven humanamente. Añádase a esta situación otro dato: la integralidad biológica de la madre no se ve en peligro ni durante la gestación/desarrollo del embrión ni durante su nacimiento.

Segunda situación: es el mismo escenario anterior, con la siguiente variante: el deterioro biológico del embrión es tal que los pronósticos científicos y médicos -con el margen de error y acierto que los caracteriza - indican, con una alta probabilidad, que el embrión seguramente morirá en el vientre materno o en el parto, sin que haya nada que la ciencia y la medicina puedan hacer para evitar ese desenlace.

Tercera situación: los escenarios anteriores, con la siguiente variante: el deterioro biológico del embrión es tal que los pronósticos científicos y médicos ofrecen una alta probabilidad de que la muerte del embrión en el vientre materno o su muerte en el parto pueden causar la muerte de la madre, ya sea por el proceso de deterioro en sí mismo o por las intervenciones médicas para corregirlo o paliarlo. 
Las tres situaciones anteriores plantean la inevitable pregunta: ¿qué hacer? Salir del paso con una respuesta general puede ser fácil y satisfactorio para quienes, sin ser ellos y ellas los que viven el problema, quieren tranquilizar su conciencia con enunciados morales abstractos que tienen validez por encima de lo que viven y deciden (o tienen que decidir) los individuos afectados por el problema.

Es que lo que debería obviarse es que las situaciones descritas (u otras de igual carácter) afectan directamente a individuos concretos (madre y embrión), cuyas condiciones de realización son bien particulares. En este sentido, en el qué hacer en cada caso particular -que es como deberían examinarse y tratarse situaciones como las descritas antes- debería contar, en primer lugar, la decisión de la madre, que es la que directamente reproduce en su seno un ser cuyo deterioro biológico o bien le impedirá desarrollarse como ser humano o bien, en el peor de los casos, pone en riesgo la propia integralidad biológica de ella.

En su decisión y valoraciones sobre qué hacer, la madre debería contar con la mejor información y apoyo científico y médico disponible, de tal modo que sea consciente de las consecuencias de lo que decida. Información y apoyo biológico y médico, e información y apoyo sociológico, psicológico y antropológico, pues tanto si decide someterse a un proceso de aborto como si decide tener a su hijo o hija, a riesgo de perder su vida, padecer lesiones a su integridad biológica o a asumir la crianza y cuido de un ser que no podrá valerse por sí mismo, todo eso debería ser hecho con el mayor conocimiento y no por ignorancia $u$ oscurantismo. Qué duda cabe que cualquiera que sea la decisión de la madre será difícil y arriesgada, y por ello se la debería acompañar y apoyar en lo que ella decida, ya que en situaciones como las descritas es imposible no reconocer que es la madre la que tiene el principal derecho y capacidad de decidir qué es lo que tiene que hacerse.

Claro está que si ella decide, en el caso en su vida corra peligro, someterse a un aborto, habrá quienes desde una moralidad abstracta le reclamarán por haber optado por la terminación de la vida de un individuo para asegurar la de ella, pero ¿qué sucede si una madre decide morir ella y que su embrión sobreviva? ¿No es acaso esto una pérdida de una vida humana por la que también hay que luchar? Claro, dirán algunos, el embrión no puede defenderse ni decidir y por eso la madre es la que decide, por lo cual aquel queda a expensas de lo que decidan otros. 
Tienen razón: es por eso que no puede generalizarse la tesis de que una madre puede decidir abortar al ser que vive en su vientre en cualquier circunstancia y condición. Una decisión así debe estar justificada por otros criterios que impidan la arbitrariedad, la irresponsabilidad y el riesgo innecesario, y que la circunscriban a casos bien particulares y delimitados. No se trata de desproteger a los embriones humanos, sino todo lo contrario: de protegerlos en su desarrollo biológico integral, que es la base para una vida psicológica y social plena. No se trata de desproteger a las madres, cuya integridad biológica-psicológica y social se puede ver seriamente dañada (en el límite, causándoles la muerte) por un severo deterioro biológico de sus embriones.

Cuando se presenta el dilema entre elegir por la vida un embrión deteriorado biológicamente y la vida de la madre, se entra en el terreno de lo ético-moral, que es el terreno de las opciones entre situaciones excluyentes. Quien enfrenta este dilema y habrá de resolverlo (y cargará con las consecuencias de su decisión) es la madre. Debería poder decidir no sólo con una buena información a la mano, sino apelando a su consciencia moral, sin que haya moralizadores que externamente la quieran obligar a que decida de una u otra manera. Porque lo moral no es algo impuesto externamente, sino algo que cada individuo elige desde su vida interior, desde sus convicciones y valores. Ya lo decía Kant: “el cielo estrellado sobre mí y la ley moral en mí". Cada individuo es dueño de su moral y nadie puede obligarlo a que asuma una moral determinada ni impedirle que tome sus propias decisiones. Este es un derecho humano fundamental que frecuentemente se violenta sin que nadie ponga freno a los guardianes de la moral de los demás.

\section{Reflexión final}

¿Es contraria la formulación anterior a los valores humanos universales? En lo absoluto. Es fiel al valor universal de la vida humana, pero en su diversidad e integralidad. No hay mejor defensa de la vida humana que la defensa de la integralidad biológica de los individuos, como base para su humanización y dignificación. ¿Quiere decirse que quienes, como embriones, tienen fallas biológicas severas deben ser abortados? No, tienen que ser, en primera instancia, cuidados y protegidos no sólo como embriones, sino a lo largo de su vida después de nacidos; protegidos realmente, desde instancias estatales, y no sólo dejados en manos de sus padres y parientes cercanos, para que ellos se las arreglen como puedan. Si sucede esto último, como es lo usual en sociedades como la nuestra, no sólo dará una carga extraordinaria a la madre y familia (que sin son pobres se hundirán más en la pobreza), sino que lo más probable es que individuos con grave deterioro biológico, sobre todo neuronal, terminen en un abandono extremo. 
Si esas fallas biológicas del embrión ponen en riesgo la integralidad biológica de la madre, al grado de amenazar su vida, se tiene que tomar una decisión acerca de la continuidad de su vida. Esta es una decisión en la cual la ciencia y la medicina deben aportar lo mejor en conocimientos a su alcance, pero es una decisión que debe recaer principalmente sobre la madre. Es una decisión moral. Por ser moral es una decisión individual.

Así las cosas, estas reflexiones no constituyen un alegato a favor del aborto (o un alegato anti-aborto), sino una defensa, primero que nada, del debate crítico e informado sobre problemas que afectan a la gente. En segundo lugar, es una defensa de los individuos humanos concretos que muchas veces son anulados desde planteamientos abstractos y genéricos. En tercer lugar, es un llamado de atención a quienes gustan de generalizaciones fáciles que van en detrimento del examen y abordaje de situaciones concretas, que afectan a personas concretas y para cuya solución no sirven las fórmulas generales, porque cada caso se requiere una solución particular. En cuarto lugar, es una crítica a quienes gustan de mezclar argumentos o dar por establecidas tesis concluyentes sobre temas controversiales y abiertos al debate. Y finalmente, es un planteamiento escéptico ante la tendencia de algunos grupos de presión a "divinizar" la realidad natural, humana y social, y que desestiman el examen y solución secular de los problemas. Pretenden poner en manos "divinas" problemas que pueden (y tienen que) ser resueltos, principalmente, con medios humanos.

\section{Bibliografía}

Bobbio, Norberto., "La declaración universal de los derechos del hombre”. En Teoría general de la política. Madrid, Trotta, 2009.

De la Fuente, Ramón., “Las bases neurológicas de la mente”. En Ramón de la Fuente et al., Biología de la mente. México, FCE, 1998.

López Moratalla, Natalia; Rodríguez, Gonzalo Herranz., “Inicio de la vida de cada ser humano. ¿Qué hace humano el cuerpo del hombre?”. Cuaderno de Bioética, XXII, 2011.

Lozano Leyva, Manuel., “La evolución selecta (La irreverencia de la ciencia)”. En Los hilos de Ariadna. Diez descubrimientos científicos que cambiaron la visión del mundo. México, Debate, 2008.

Luria, Alexander R., El cerebro humano y los procesos psíquicos. Barcelona, Fontanella, 1979. 
Merani, Alberto L., Estructura y dialéctica de la personalidad. México, Grijalbo, 1978.

Nieves, José Manuel., Hablemos de ciencia. Madrid, EDAF, 2006.

Popper Karl., "De la tolerancia” (1981). En Después de la sociedad abierta. Buenos Aires, Paidós, 2010.

Rodríguez, Darío; Torres Javier., "Autopoiesis, la unidad de una diferencia: Luhmann y Maturana”. Sociología, Porto Alegre, años 5, No. 9, jan/jun 2003.

Wallon, Henri., La evolución psicológica del niño. México, Grijalbo, 1977. 